\title{
Microarray expression profile of IncRNAs and the upregulated ASLNC04080 IncRNA in human endometrial carcinoma
}

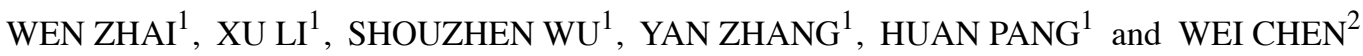 \\ ${ }^{1}$ Center for Translational Medicine, The First Affiliated Hospital, School of Medicine, \\ Xi'an Jiaotong University; ${ }^{2}$ Department of Laboratory Medicine, The First Affiliated Hospital, \\ School of Medicine, Xi'an Jiaotong University, Xi'an, P.R. China
}

Received November 25, 2014; Accepted January 16, 2015

DOI: 10.3892/ijo.2015.2897

\begin{abstract}
Long non-coding RNAs (lncRNAs) have been recognized as a regulator of gene expression, and the deregulation of lncRNAs have been reported to be correlated with carcinogenesis and cancer progression. To explore the function of IncRNA in endometrial carcinoma, we analyzed the expression profiles of lncRNAs and coding genes in 3 paired endometrial carcinoma and adjacent non-tumor tissues, using a microarray. The results of microarray analysis indicated a significant difference in lncRNA and coding gene expression between endometrial carcinoma and their paired adjacent nontumor tissues. A total of 53 lncRNAs (fold change $>2.0$, p-value $<0.05)$ were found to be differently expressed in endometrial carcinoma compared to the normal controls. Among these ASLNC04080 was the most significantly upregulated lncRNA in microarray data, highly expressed in 22 out of 24 endometrial carcinoma tissues and HEC-1-B cell line. ASLNC04080 is $1867 \mathrm{nt}$ in length, consist of 6 exons, and locates at $1 \mathrm{p} 35.3$ (chr1: -28905061 - -28909492). In addition, 46 coding gene transcripts were differentially expressed (fold change $>2.0$, p-value $<0.05$ ) between endometrial carcinoma and adjacent non-tumor tissues. Pathway and gene ontology analysis demonstrated that these deregulated transcripts were involved in multiple signal pathways, biological processes, cellular components and molecular functions. Moreover, the ASLNC04080 lncRNA expression was correlated with 19 coding genes, and may contribute to endometrial carcinoma genesis and progression by co-regulating with coding gene. Expression inhibition of IncRNA ASLNC04080 in HEC-1-B cells caused repression of cell proliferation, increased cell apoptosis, and G1 phase arrest. These results suggested a potential function of ASLNC04080 in endometrial carcinoma genesis and progression.
\end{abstract}

Correspondence to: Professor Wei Chen, Department of Laboratory Medicine, The First Affiliated Hospital, School of Medicine, Xi'an Jiaotong University, 277 West Yanta Road, Xi'an 710061, P.R. China E-mail: chenwei2011xjtu@gmail.com

Key words: LncRNA, endometrial carcinoma, ASLNC04080, HEC-1-B, proliferation

\section{Introduction}

Endometrial carcinoma, comprising of several types of malignancies arise from the endometrium or lining of the uterus, is the most common gynecologic malignancy among women in the United States, with an estimated 52,630 new case and 8,590 deaths in 2014 (1). Endometrial carcinoma cases in Chinese women increased in the last decade. Based on clinical features and pathogenesis endometrial carcinomas have been classified into two types (2). Type I endometrial carcinomas occur commonly in perimenopausal women, with low grade, related to obesity and estrogen exposure. Type II endometrial carcinomas are more common in older women, unrelated to hormone excess, with a worse outcome than Type I. Previous studies have reported that various gene mutations, and expression deregulation are related to endometrial carcinoma genesis. PTEN and K-ras mutations occur in Type I endometrial carcinomas, often with Wnt, AKT and PI3KCA deregulation. TP53 and PPP2R1A mutations are frequent in Type II endometrial carcinomas, with HER2/neu overexpression and p16 inactivation $(3,4)$.

LncRNAs are a spectrum of RNAs transcripted by RNA polymerase II, but not translated into proteins, with more than 200 nucleotides in length. LncRNAs which have previously been identified as transcription noise are proved to be involved in the process of multiple gene expression regulation $(5,6)$. Increasing evidence suggests that the deregulation of lncRNAs is linked to disease, especially carcinoma genesis. UCA1 (7-10) upregulated in bladder carcinoma, is a functional lncRNA molecule involved in cell growth, cell cycle, cell invasion and tumorigenesis. LncRNA AFAP1-AS1 (11) is hypomethylated and upregulated in Barrett's esophagus (BE), esophageal adenocarcinoma (EAC) tissues and cell lines. Inhibition of its expression in EAC cells was able to diminish cell growth, migration, and invasion, as well as increase apoptosis. MALAT1 (12) is first discovered in non-small cell lung cancer and its over-expression associates with high metastatic potential and poor patient prognosis in variety of cancer. A recent report showns that the promoter hypermethylation silencing of tumor suppressor PCDH10 contributed to MALAT1 upregulation in endometrioid endometrial cancer (EEC) (13).

The mechanism of endometrial carcinoma genesis is complex and related with multiple gene mutation and deregulation. The exploration of gene expression profile, especially the 
potential functional lncRNA will help to gain better knowledge and to discover new therapeutic candidates for endometrial carcinoma. We performed a microarray analysis to study the expression of lncRNAs and coding genes in 3 endometrial carcinomas and their paired adjacent non-tumor tissues. Our result demonstrated that the expression profile of lncRNAs is significantly different between endometrial carcinomas and non-tumor endometrium. The novel ASLNC04080 lncRNA is upregulated in endometrial carcinomas and HEC-1-B cell line. Additionally the deregulation of coding genes was also detected in endometrial carcinomas, and these deregulated coding transcripts were involved in multiple biological processes, cellular components, molecular functions and pathways which were related to carcinogenesis and cancer progression. We constructed a co-expression network of lncRNAs and coding gene transcripts based on the expression level relation between lncRNAs and coding gene transcripts. According to the co-expression network ASLNC04080's expression was correlated to 19 coding transcripts, showing a potential co-regulation function of lncRNA ASLNC04080. Taken together, these results suggest the altered expression levels of lncRNAs may contribute to endometrial carcinomas genesis and multiple molecular processes. In addition, ASLNC04080 could be a functional lncRNA molecule with potential use as biomarker or therapeutic target.

\section{Materials and methods}

Patient samples. All human endometrial carcinomas and their paired adjacent nontumor tissues were obtained from patients of the First Affiliated Hospital, School of Medicine of Xi'an Jiaotong University. Tissue samples were collected with informed consent from patients, as approved by the Hospital Ethics Committees. All tissue samples were pathologically confirmed. Three pairs of these patient samples were randomly selected for human lncRNA microarray analysis.

DNA microarray. RNA quality was assessed by Nanodrop ND-1000 and RNA integrity was assessed using standard denaturing agarose gel electrophoresis. The RNA extraction was performed by KangChen Bio-tech, Shanghai, China.

The Human 12x135 k Long Non-coding RNA Array was manufactured by Roche NimbleGen. Each array represents all long transcripts, both protein coding mRNAs and lncRNAs (long non-coding RNAs) in the human genome. More than 23000 lncRNAs are collected from the authoritative data sources including NCBI RefSeq, UCSC, RNAdb, lncRNAs from literature and UCRs. The microarray analysis was performed by KangChen Bio-tech.

RNA labeling and array hybridization. Double-strand cDNA (ds-cDNA) was synthesized from $5 \mu \mathrm{g}$ of total RNA using an Invitrogen SuperScript ds-cDNA synthesis kit in the presence of 100 pmol oligo dT primers. ds-cDNA was cleaned and labeled in accordance with the Nimblegen Gene Expression Analysis protocol (Nimblegen Systems, Inc., Madison, WI, USA). Briefly, ds-cDNA was incubated with $4 \mu \mathrm{g}$ RNase A at $37^{\circ} \mathrm{C}$ for $10 \mathrm{~min}$ and cleaned using phenol:chloroform:isoamyl alcohol, followed by ice-cold absolute ethanol precipitation.
The purified cDNA was quantified using a nanodrop ND-1000. For Cy3 labeling of cDNA, the Nimblegen One-Color DNA labeling kit was used according to the manufacturer's guideline detailed in the Gene Expression Analysis protocol (Nimblegen Systems, Inc.). ds-cDNA $(1 \mu \mathrm{g})$ was incubated for $10 \mathrm{~min}$ at $98^{\circ} \mathrm{C}$ with $1 \mathrm{OD}$ of $\mathrm{Cy} 3-9 \mathrm{mer}$ primer. Then, $100 \mathrm{pmol}$ of deoxynucleoside triphosphates and 100 units of the Klenow fragment (New England Biolabs, Ipswich, MA, USA) were added and the mix incubated at $37^{\circ} \mathrm{C}$ for $2 \mathrm{~h}$. The reaction was stopped by adding 0.1 volume of $0.5 \mathrm{M}$ EDTA, and the labeled ds-cDNA was purified by isopropanol/ethanol precipitation. Microarrays were hybridized at $42^{\circ} \mathrm{C}$ for $16-20 \mathrm{~h}$ with $4 \mu \mathrm{g}$ of $\mathrm{Cy} 3$ labelled ds-cDNA in Nimblegen hybridization buffer/hybridization component $\mathrm{A}$ in a hybridization chamber (Hybridization System - Nimblegen Systems, Inc.). Following hybridization, washing was performed using the Nimblegen Wash Buffer kit (Nimblegen Systems, Inc.). After being washed in an ozone-free environment, the slides were scanned using the Axon GenePix 4000B microarray scanner. The microarray analysis was performed by KangChen Bio-tech.

Data analysis. Slides were scanned at $5 \mu \mathrm{m} /$ pixel resolution using an Axon GenePix 4000 B scanner (Molecular Devices Corp.) piloted by GenePix Pro 6.0 software (Axon). Scanned images (TIFF format) were then imported into NimbleScan software (version 2.5) for grid alignment and expression data analysis. Expression data were normalized through quantile normalization and the Robust Multichip Average (RMA) algorithm included in the NimbleScan software. The Probe level (*_norm_RMA.pair) files and mRNA level (*_RMA.calls) files were generated after normalization. All mRNA level files were imported into Agilent GeneSpring Software (version 11.0) for further analysis. Differentially expressed lncRNAs and mRNAs were identified through Fold Change filtering. Hierarchical clustering was performed using the Agilent GeneSpring GX software (version 11.0). GO analysis and Pathway analysis was performed using the standard enrichment computation method. The analysis was performed by KangChen Bio-tech.

GO analysis. The Gene Ontology project provides a controlled vocabulary to describe gene and gene product attributes in any organism (http://www.geneontology.org). The ontology covers three domains: Biological Process, Cellular Component and Molecular Function. Fisher's exact test is used to find if there is more overlap between the DE list and the GO annotation list than would be expected by chance. The p-value denotes the significance of GO terms enrichment in the DE genes. The lower the $p$-value, the more significant the GO term ( $p \geq 0.05$ is recommended).

Pathway analysis. Pathway analysis is a functional analysis mapping genes to KEGG pathways. The p-value (EASE-score, Fisher p-value or Hypergeometric-p-value) denotes the significance of the Pathway correlated to the conditions. The lower the p-value, the more significant the pathway is (the recommend p-value cut-off is 0.05 ).

Co-expression network. We constructed a coding-noncoding gene co-expression network to investigate the relation between 
lncRNAs and their coding genes, 6 lncRNAs up- or downregulated in endometrial carcinoma tissues were selected to draw the network. i) The data were preprocessed by using the median gene expression value of all transcripts expressed from the same coding gene, without special treatment of the lncRNA expression value. ii) Then the data were screened for differentially expressed lncRNAs and mRNAs and removed from the dataset. iii) The R-value was used to calculate the correlation coefficient of the PCC between lncRNA and coding genes (only lncRNA-coding PCC, not including lncRNA-lncRNA or coding-coding PCC). iv) Based on Pearson's correlation coefficient selecting $\mathrm{PCC} \geq 0.95$ as meaningful related pair v) The co-expression network was drawn using Cytoscape. In the network, a round node represents the coding gene, a box node represents the IncRNA, a red node represents an upregulated lncRNA/mRNA and a green node represents an under-regulated lncRNA/mRNA. A red solid line indicates a positive correlation, and a blue dashed line indicates a negative correlation.

RNA extraction and cell culture. Total RNA from tissue samples, whole blood and cells was extracted using TRIzol reagent (Invitrogen, Carlsbad, CA, USA). RNA concentration and integrity were determined by spectrophotometry and standard RNA gel electrophoresis.

The human endometrial carcinoma (HEC-1-B); cervical carcinoma (Siha HeLa) and ovarian cancer (3AO SKOV3) cell lines were cultured in RPMI-1640 medium (Gibco-BRL, Gaithersburg, MD, USA) supplemented with $10 \%$ bovine calf serum. Cultures were maintained at $37^{\circ} \mathrm{C}$ in a humidified atmosphere with $5 \% \mathrm{CO}_{2}$.

Expression analysis of ASLNC04080 by RT-PCR and $q R T-P C R$. Total RNA isolated from tissue samples, whole blood and cells was reverse transcribed by using PrimeScript ${ }^{\mathrm{TM}}$ RT Reagent kit with gDNA Eraser (Takara, Dalian, China). Takara Taq $^{\mathrm{TM}}$ (Takara) was used for 32 PCR cycles, annealing temperature was $65^{\circ} \mathrm{C}$. SYBR ${ }^{\circledR}$ Premix Ex Taq ${ }^{\mathrm{TM}}$ was used for real-time PCR, annealing temperature was $61^{\circ} \mathrm{C}$. Primer sequences were as follows: ASLNC04080: forward primer, 5'-CGCTATGTGTGGTGCCTGGGGTG-3' and reverse primer, 5'-CAGCGCCTGAGTGGGTTTCGG-3'; 18S: forward primer, 5'-GCTCAGCGTGTGCCTACCCTAC-3' and reverse primer, 5'-GTAGTAGCGACGGGCGGTGTGTA-3'.

Rapid amplification of cDNA ends (5'- and 3'-RACE). One microgram of total RNA of whole blood was purified further by treating with RNase-Free DNaseI (Takara), then reverse transcribed with the SMART RACE cDNA Amplification kit (Clontech, Mountain View, CA) according to manufacturer's instructions. Specific 5'- and 3'-RACE cDNA ends were amplified with the universal primer mix provided in the kit and gene specific primers (GSPs) with the advantage 2 PCR polymerase mix (Clontech). The PCR products were subcloned into pGEM-T Easy vector (Promega, Madison, WI, USA) and several recombinant clones were isolated for sequencing. The GSP sequences: 5'RACE Gene-Specific Primers (Out Primer 5'-AGCGCCTGAGTGGGTTTCGG-3'; Inner Primer 5'-GGG GGTCATACTCCCCGAAAGG-3'). 3'RACE Gene-Specific Primers (Out Primer 5'-TTAATAGATTAGGCACAGGA
TGGGT-3'; Inner Primer 5'-CAGGATGGGTGTTTAATTC TCGGCAA-3').

Amplification of truncated full length cDNA sequence. Total RNA isolated from whole blood and cells was reverse transcribed by using PrimeScript II 1st Strand cDNA Synthesis kit (Takara). The Takara LA Taq ${ }^{\circledR}$ (Takara) was used for 30 cycles PCR amplification, annealing temperature was $62^{\circ} \mathrm{C}$. The truncated full length cDNA sequence primers: forward primer 5'-ACCGCACCCGGCAGTAGTAC-3', reverse primer 5'-ATT GATCACCTCTGAAGTTCAGTAGCA-3'. The PCR products were subcloned into pGEM-T Easy vector (Promega) and several recombinant clones were isolated for sequencing.

Small interfering RNA transfection. Three different small interfering RNAs (siRNA) targeted ASLNC04080 (si-RNA616, si-RNA1315, si-RNA1535; (Gene Pharma, Shanghai, China) and nonsense siRNA control were transected to HEC-1-B cells by X-tremeGENE siRNA Transfection Reagent (Roche, Mannheim, Germany). The sequences of the 3 siRNAs were as follows: si-RAN616: 5'-CAGGGUUCAUUUCCAGACU-3'; si-RNA1315: 5'-GGCGUACUUAAGCAGAUGA-3'; si-RNA1535: 5'-GGAGUUGGGACAAUCUCUA-3'. The knockdown effect of siRNA was detected by qRT-PCR.

Cell proliferation assays. HEC-1-B cells were plated 3000 cells per well onto 96-well plates, after $24 \mathrm{~h}$ siRNA1535 and nonsense siRNA control were transfected. Every $24 \mathrm{~h}$ cell proliferation reagent CCK8 (Dojindo, Kumamoto, Japan) was added $10 \mu \mathrm{l}$ per well and then incubated at $37^{\circ} \mathrm{C}$ for $2 \mathrm{~h}$. Optical density was measured at $450 \mathrm{~nm}$ using a microplate reader (EnSpire, USA), and the proliferation activity curve was drawn.

Cell apoptosis assays. HEC-1-B cells were plated at $15 \times 10^{4}$ cells per well into 6 -well plates. After $48 \mathrm{~h}$ of treatment with siRNA-1535 and nonsense siRNA control, HEC-1-B cells were harvested and stained with Annexin V and PI using Annexin V-FITC/PI apoptosis detection kits (Beyotime, Haimen, China) and then examined by flow cytometry (BD FACSCantoII, BD Biosciences, San Jose, CA, USA). Cellular proteins were extracted $48 \mathrm{~h}$ after siRNA transfection. Caspase-3 (Cell Signaling Technology, Danvers, MA) expression was detected by western blotting.

Cell cycle analysis. HEC-1-B cells were plated at $15 \times 10^{4}$ cells per well into 6-well plates. After $48 \mathrm{~h}$ of treatment with siRNA1535 and nonsense siRNA control, HEC-1-B cells were harvested, washed with ice-cold phosphate-buffered saline, fixed with $70 \%$ ethanol overnight, and pretreated with $5 \mathrm{mg} / \mathrm{ml}$ ribonuclease for $30 \mathrm{~min}$ at $37^{\circ} \mathrm{C}$ and then stained with PI $(100 \mu \mathrm{g} / \mathrm{ml})$. Cell cycle profile was determined by flow cytometry (BD FACSCanto II, BD Biosciences) analysis of DNA content of cell nuclei.

\section{Results}

ASLNC04080 is upregulated in endometrial carcinoma and cell lines. We performed a microarray analysis of lncRNA in 3 paired endometrial carcinoma and adjacent non-tumor 
A

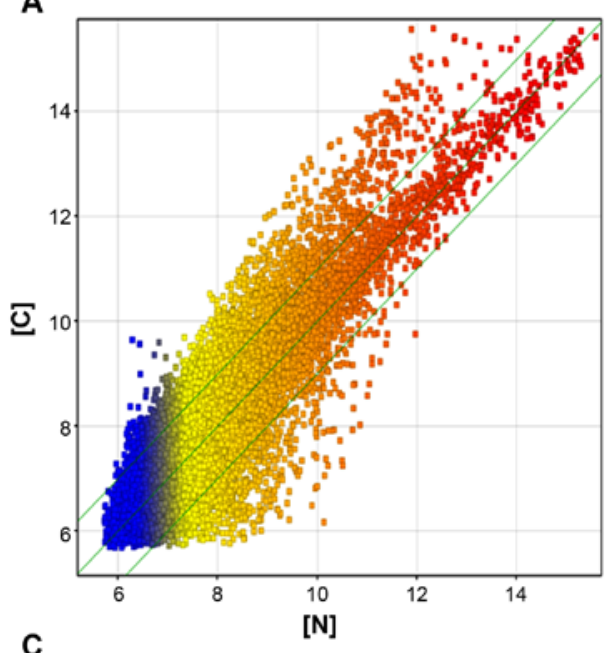

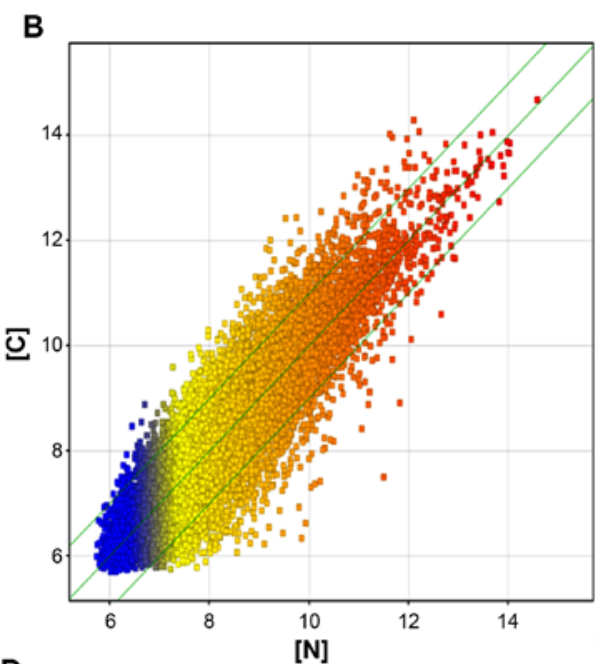

D

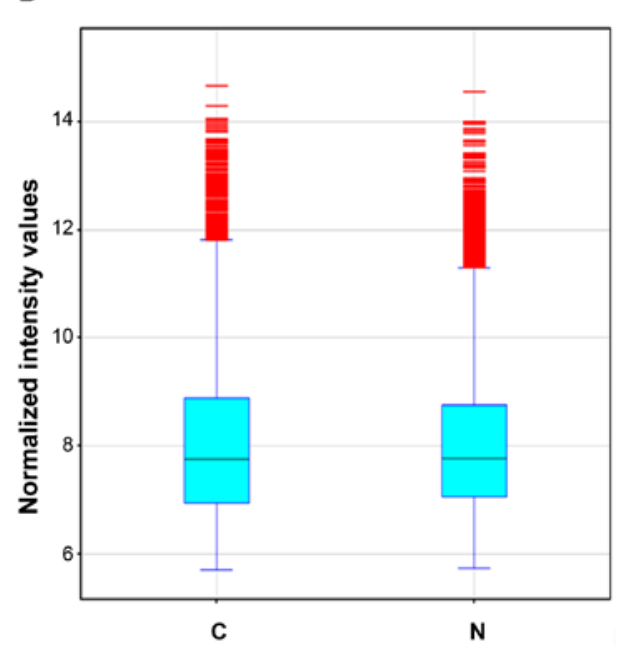

Figure 1. The gene expression profile difference in 3 paired endometrial carcinoma [C] and adjacent nontumor tissues [N]. The scatter plot is a visualization method used for assessing the lncRNA (A) and mRNA (B) expression variations between endometrial carcinoma [C] and paired adjacent nontumor tissues [N]. The values of the $\mathrm{X}$ and $\mathrm{Y}$ axes in the scatter plot are the averaged normalized signal values of the group (log2 scaled). The green lines represent fold-change (the default fold change given is 2.0). The box plot is a convenient way to quickly visualize the distribution of a dataset for the lncRNAs (C) and the mRNAs (D) profiles. After normalization, the distributions of $\log 2$ ratios among the groups are nearly the same.

tissues. In the lncRNA expression profiling data, a total of 23,837 lncRNAs expressed in endometrial carcinoma were detected. A comparison of IncRNA expression level between endometrial carcinoma and adjacent non-tumor tissues identified 53 lncRNAs which were significantly differentially expressed (fold change $\geq 2.0, \mathrm{p} \leq 0.05$ ) (Fig. $1 \mathrm{~A}$ and $\mathrm{C}$ and Table I). ASLNC04080 was the most upregulated lncRNA (fold change $=3.38, \mathrm{p}=0.038$ ), and CD109474 was the most downregulated lncRNA (fold change $=4.72, \mathrm{p}=0.034$ ) in the endometrial carcinoma group.

The RT-PCR result showed ASLNC04080 expression difference in 3 paired endometrial carcinoma and adjacent non-tumor tissues which we used for microarray analysis (Fig. 2B). We evaluated the expression level of lncRNA ASLNC04080 in 24 paired endometrial carcinoma and adjacent non-tumor tissues as well as gynecological cancer cell lines. In our result ASLNC04080 expression level in endometrial carcinoma tissues was upregulated in 22 out of 24 paired samples (Fig. 2A). The ASLNC04080 transcripts were also detected in endometrial carcinoma (HEC-1-B), cervical carcinoma (Siha HeLa) and ovarian cancer (3AO SKOV3) cell lines (Fig. 2C). Additionally, according to UCSC information, ASLNC04080 was expressed in a series of lymphocytes (Fig. 2D). We detected the expression of ASLNC04080 in whole blood from both endometrial carcinoma patients as well as healthy people (Fig. 2E).

Sequence structure of ASLNC04080. The 5'RACE and 3'RACE were performed to acquire 5'-end and 3'-end cDNA sequence of ASLNC04080 (Fig. 3A). According to the overlapping region, we spliced 5'-end (744 bp) and 3'-end (1488 bp) sequence forming the full length cDNA sequence (1867 bp) (Fig. 3B). The sequence message was submitted to NCBI, GeneBank, Accession no. KJ782215. The ASLNC04080 cDNA sequence identity is $99.5 \%$ of the part human chromosome 1 cosmid (chr1: -28905061 - -28909492) sequence, by mapping with Blat search program from UCSC. The full length ASLNC04080 cDNA contained 6 exons mapped with the 1 p35.3 (Fig. 3C), and the identity is 99\% (Query cover $39 \%$ ) of the SNHG12. 
Table I. Differentially expressed lncRNAs with $>2$-fold change in 3 paired endometrial carcinoma tissues (C) vs. adjacent nontumor tissues $(\mathrm{N})$.

\begin{tabular}{|c|c|c|}
\hline SEQ_ID & $\log 2$ fold change $\mathrm{C} / \mathrm{N}$ & Regulation \\
\hline ASLNC00294 & 2.5359635 & Up \\
\hline ASLNC02239 & 2.0272071 & Up \\
\hline ASLNC04080 & 3.3796694 & Up \\
\hline ASLNC06245 & 2.5081081 & Up \\
\hline ASLNC06537 & 2.5098338 & Up \\
\hline ASLNC08884 & 2.236056 & Up \\
\hline ASLNC09130 & 2.2931793 & $\mathrm{Up}$ \\
\hline ASLNC09507 & 2.4517279 & Up \\
\hline ASLNC10247 & 2.355146 & Up \\
\hline ASLNC12496 & 2.2451406 & Up \\
\hline ASLNC14462 & 2.097873 & Up \\
\hline ASLNC14832 & 2.020886 & Up \\
\hline ASLNC15527 & 2.5785253 & Up \\
\hline ASLNC17047 & 2.3866124 & Up \\
\hline ASLNC17464 & 2.1540515 & Up \\
\hline ASLNC23065 & 2.1494098 & Up \\
\hline ASLNC23333 & 2.0054722 & Up \\
\hline ASLNC23414 & 2.4249542 & $\mathrm{Up}$ \\
\hline ASLNC23671 & 2.4036572 & Up \\
\hline AV732045 & 2.1128297 & Up \\
\hline BC146594 & 2.3366451 & $\mathrm{Up}$ \\
\hline BF448178 & 2.5298557 & Up \\
\hline BF958740 & 2.079252 & $\mathrm{Up}$ \\
\hline BI046482 & 2.8131595 & Up \\
\hline BI520265 & 2.009207 & Up \\
\hline BX642924 & 3.1237326 & Up \\
\hline BX648912 & 2.0242465 & Up \\
\hline DA195606 & 2.1546383 & Up \\
\hline DB269443 & 2.336296 & $\mathrm{Up}$ \\
\hline DB335254 & 2.1803222 & Up \\
\hline DB341724 & 2.82081 & $\mathrm{Up}$ \\
\hline DB349701 & 2.6501746 & Up \\
\hline H44233 & 2.1850893 & Up \\
\hline exon2439 & 2.012377 & Up \\
\hline exon 2817 & 2.0926008 & Up \\
\hline exon3497 & 2.1918285 & Up \\
\hline exon418 & 2.4487195 & Up \\
\hline exon4652 & 2.4781675 & Up \\
\hline exon844 & 2.45636 & Up \\
\hline ASLNC00038 & 2.559887 & Down \\
\hline ASLNC00087 & 2.1803436 & Down \\
\hline ASLNC04117 & 2.09159 & Down \\
\hline ASLNC05193 & 2.5719202 & Down \\
\hline ASLNC05485 & 2.8765132 & Down \\
\hline ASLNC09591 & 2.8102934 & Down \\
\hline ASLNC10223 & 2.6993935 & Down \\
\hline ASLNC10915 & 2.2386236 & Down \\
\hline ASLNC14186 & 2.162685 & Down \\
\hline ASLNC18394 & 2.2218604 & Down \\
\hline ASLNC21513 & 2.0064554 & Down \\
\hline BF507708 & 2.3711028 & Down \\
\hline CD109474 & 4.7178984 & Down \\
\hline HMlincRNA1454 & 2.032924 & Down \\
\hline
\end{tabular}

P-values $<0.05$ were considered significant.
Table II. Differentially expressed mRNAs with $>2$-fold change in 3 paired endometrial carcinoma tissues (C) vs. adjacent nontumor tissues $(\mathrm{N})$.

\begin{tabular}{|c|c|c|}
\hline Gene symbol & $\log 2$ fold change $\mathrm{C} / \mathrm{N}$ & Regulation \\
\hline COL1A2 & 2.1063402 & Up \\
\hline PLA2G1B & 2.4415922 & Up \\
\hline OR1S1 & 2.391917 & Up \\
\hline GEMIN7 & 2.4388766 & Up \\
\hline C10orf114 & 2.1364949 & Up \\
\hline FIGNL2 & 3.4194834 & $\mathrm{Up}$ \\
\hline IL31 & 2.0702891 & Up \\
\hline FAM23A & 2.0272226 & $\mathrm{Up}$ \\
\hline ACOX3 & 2.8613539 & Up \\
\hline NKPD1 & 2.0944095 & Up \\
\hline FAM148C & 2.1054876 & Up \\
\hline AKR1C1 & 2.4084988 & Up \\
\hline TLE2 & 2.0259166 & $\mathrm{Up}$ \\
\hline $\mathrm{CDH7}$ & 2.0604987 & Up \\
\hline HOXC6 & 2.1476102 & Up \\
\hline C9orf61 & 2.0307186 & Up \\
\hline KIR2DL1 & 2.1328676 & Up \\
\hline TINAG & 2.2404068 & Up \\
\hline MGRN1 & 2.1519182 & Up \\
\hline CCR10 & 3.6094117 & Up \\
\hline EMID2 & 2.6075573 & Up \\
\hline BAX & 2.5370033 & Up \\
\hline DAND5 & 2.2088263 & Up \\
\hline HOXC6 & 2.1748328 & Up \\
\hline ZBTB12 & 2.3850377 & Up \\
\hline SCN1B & 2.1365902 & Up \\
\hline GCH1 & 2.2663758 & Down \\
\hline H2BFWT & 2.1060047 & Down \\
\hline DDAH1 & 2.0587702 & Down \\
\hline LOC120376 & 2.1094232 & Down \\
\hline CRYM & 3.8512769 & Down \\
\hline RDH5 & 2.0616512 & Down \\
\hline SLC4A4 & 2.5983744 & Down \\
\hline EGR3 & 2.0082827 & Down \\
\hline TSPAN8 & 2.9661324 & Down \\
\hline APBA3 & 2.10935 & Down \\
\hline XBP1 & 2.010461 & Down \\
\hline SERPINB3 & 2.4469104 & Down \\
\hline KRT23 & 2.4278355 & Down \\
\hline SERTAD4 & 2.100912 & Down \\
\hline KIAA1324 & 3.5217378 & Down \\
\hline SLC38A5 & 2.3809822 & Down \\
\hline PARP15 & 2.4587605 & Down \\
\hline CACNB2 & 3.3419204 & Down \\
\hline ZNF320 & 2.033858 & Down \\
\hline PRSS12 & 2.3177733 & Down \\
\hline
\end{tabular}

P-values $<0.05$ were considered significant.

The truncated full length cDNA sequence (184-1838, $1655 \mathrm{bp}$ ) was acquired from human whole blood and endometrial carcinoma cell line HEC-1-B (Fig. 3D), and identity 


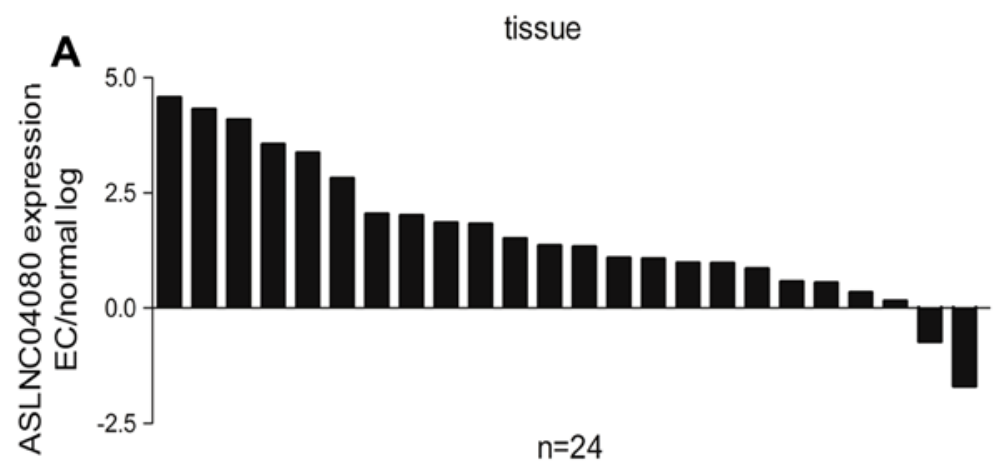

B
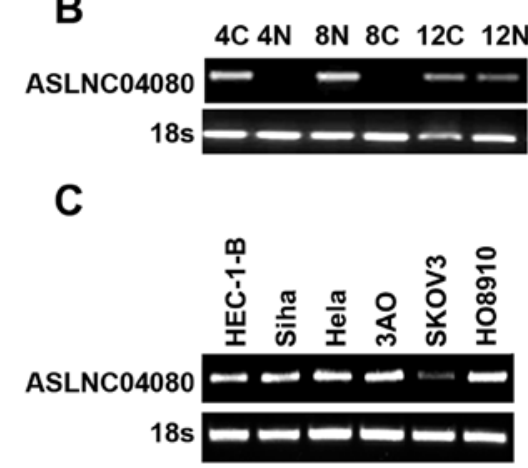

D colorectal adenocarcinoma leukemia chronic myelogenous( $(k 562)$ lymphoma Burkitts Daudi leukemia promyelocytic(hl60) lymphoma Burkitts Raj 721 B lymphoblasts leukemia lymphoblastic(molt4)

E

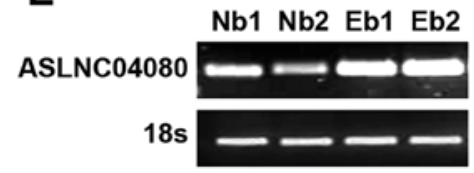

PB-CD19+ Bcells PB-CD8+ Tcells PB-CD4+ Tcells $\mathrm{PB}-\mathrm{CD} 56+\mathrm{NKCells}$ PB-CD14+ monocytes PB-BDCA4+ dentritic cells

Figure 2. ASLNC04080 was upregulated in endometrial carcinoma tissues. (A) ASLNC04080 expression was increased in 92\% endometrial carcinoma tissues (EC) (22/24) vs. adjacent nontumor tissues (normal), qRT-PCR. (B) ASLNC04080 expression RT-PCR result conformed to the microarray data. (C) ASLNC04080 was expressed in endometrial carcinoma cell line (HEC-1-B), cervical carcinoma cell lines (Siha, HeLa) and ovarian cancer cell lines (3AO, SKOV3, HO9810), RT-PCR. (D) ASLNC04080 expression profile information from UCSC microarray expression data. (E) ASLNC04080 expression was detected in whole blood of endometrial carcinoma patients (Eb) and healthy people (Nb), RT-PCR.

of 99\% (Query cover 88\%) of the full length ASLNC04080 cDNA (KJ782215).

Coding gene expression profile in endometrial carcinoma. The microarray analysis also included information on the coding gene. A total of 18,738 coding transcripts (mRNA) could be detected in the 3 paired tissue samples. Compared the mRNA expression level between endometrial carcinoma and adjacent non-tumor tissues, there were 46 mRNA differentially expressed; of those 26 were upregulated and 20 were downregulated in the endometrial carcinoma group (fold change $\geq 2.0, \mathrm{p} \leq 0.05$ ) (Fig. $1 \mathrm{~B}$ and D; and Table II).

With Pathway and Gene Ontology analysis we found that these deregulated coding genes were involved in multiple pathways and gene ontology. Pathway analysis indicated that 12 pathways corresponded to upregulated transcripts (Table III), and 12 pathways corresponded to downregulated transcripts (Table IV). Ras signaling pathway corresponded to 15 transcripts from both up- and down-regulated data (Tables III and IV).

Gene ontology (GO) analysis was preformed to show that the differently expressed mRNA transcripts were associated with biological processes (BP), cellular components (CC) and molecular function (MF) (Fig. 4). Progesterone metabolic process is one of the most frequent fold enrichment biological processes. There were 13 upregulated and 18 downregulated transcripts involved in biological process of wound healing. Deregulated transcripts were involved in the molecular function voltage-gated channel activity, including voltage-gated ion channel activity, voltage-gated channel activity, voltagegated cation channel activity and voltage-gated calcium channel activity

Expression of ASLNC04080 correlates with the coding genes. Based on the correlation analysis between differently expressed lncRNAs and mRNAs, we constructed a codingnon-coding gene co-expression network. Four upregulated and 2 downregulated lncRNAs in endometrial carcinoma tissues were selected to draw the network. The expression of 289 mRNAs was related (Pearson's correlation coefficients: PCC $\geq 0.95$ ) to these 6 lncRNAs (Fig. 5).

ASLNC04080 expression level was correlated with 19 coding gene transcripts (Fig. 5). Besides, these coding genes were involved in multiple pathways and gene ontology. For example CCR10 was upregulated in endometrial carcinoma and positively correlated with ASLNC04080 expression 

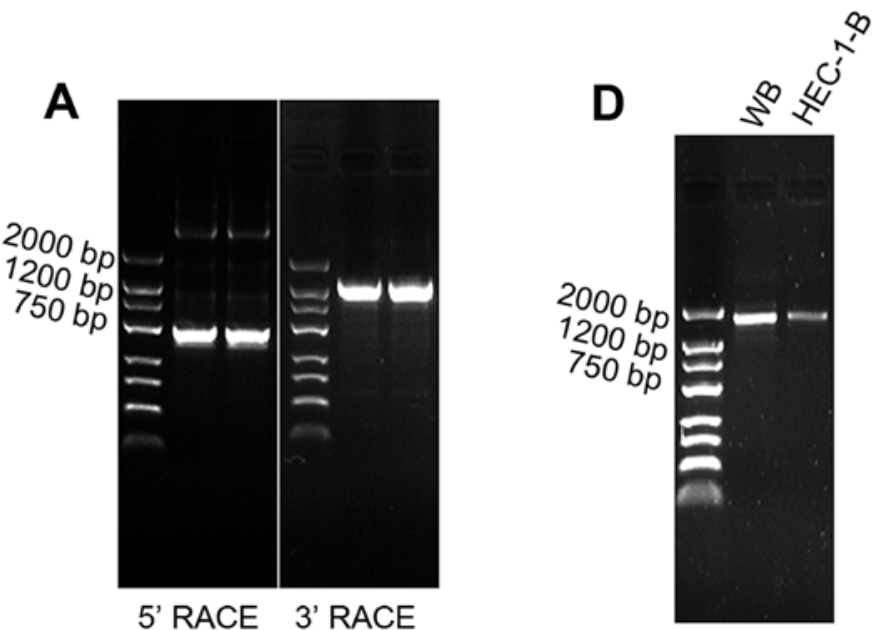

B

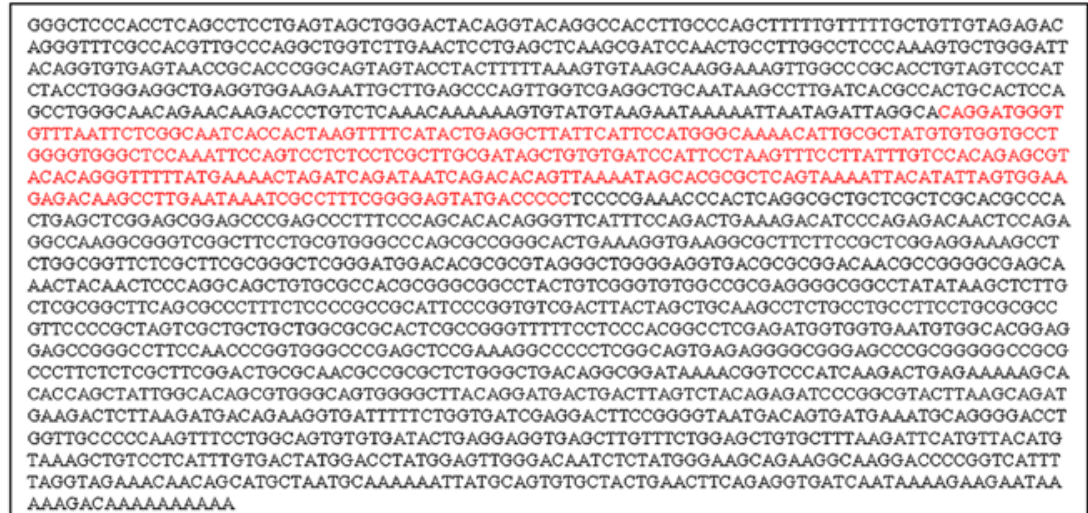

C

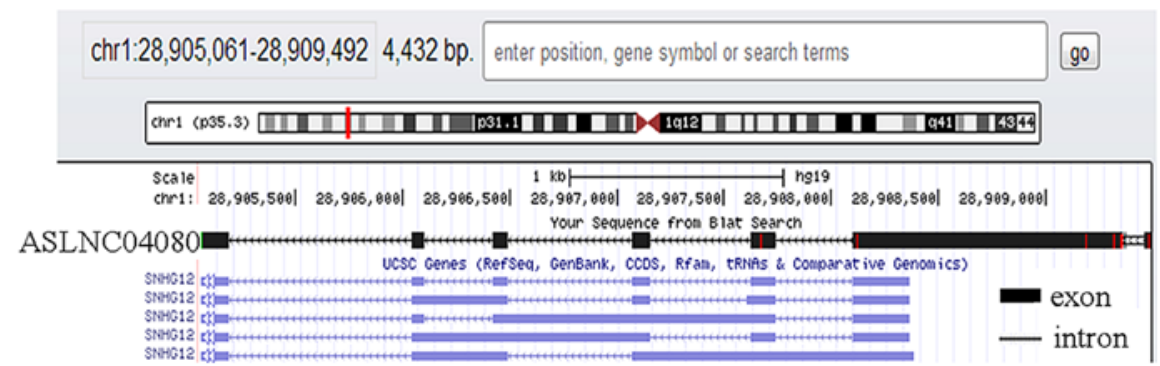

Figure 3. The sequence structure of ASLNC04080. (A) 5'RACE and 3'RACE were performed to acquire the 5'-end and 3'-end cDNA sequence of ASLNC04080. The PCR products were sequenced. (B) The full length cDNA sequence of ASLNC04080 (1867 bp). Red zone is the overlapping region of the 5 '-end (744 bp) and 3'-end (1488 bp) sequence. (C) UCSC Blat search program. ASLNC04080 contained 6 exons and 5 introns, located at 1p35.3 and identity of 99\% (Query cover 39\%) with the SNHG12. (D) ASLNC04080's truncated full length cDNA sequence (184-1838, 1655 bp) amplified from human whole blood (Wb) and endometrial carcinoma cell line HEC-1-B.

( $\mathrm{PCC}>0.95)$, and participated in intestinal immune network for IgA production. In addition, SYCP2 negatively correlated with ASLNC04080 expression (PCC >0.95), involved in the pathway of the cell cycle. These results implicated that ASLNC04080 has an inter-regulation relation with the coding gene, and could be a potential functional molecule in endometrial carcinoma genesis and progression.

Inhibition of ASLNC04080 expression influences HEC-1-B cell proliferation, apoptosis and cell cycle. We used 3 different siRNAs to inhibit ASLNC04080 expression in human endome- trial carcinoma cell line HEC-1-B. All 3 siRNAs were tested to have $>50 \%$ reduction efficiency of ASLNC04080 expression in HEC-1-B, and siRNA-1535 could reduce by $>80 \%$ the ASLNC04080 expression (Fig. 6A). Therefore, we performed several in vitro assays to determine the functional consequences of ASLNC04080 by inhibiting ASLNC04080 expression via siRNA-1535.

Compared with cells transfected with negative control siRNA, HEC-1-B cell proliferation was significantly suppressed within 48 h (Fig. 6B) by inhibiting ASLNC04080 expression. The cell apoptosis assays were examined by flow 

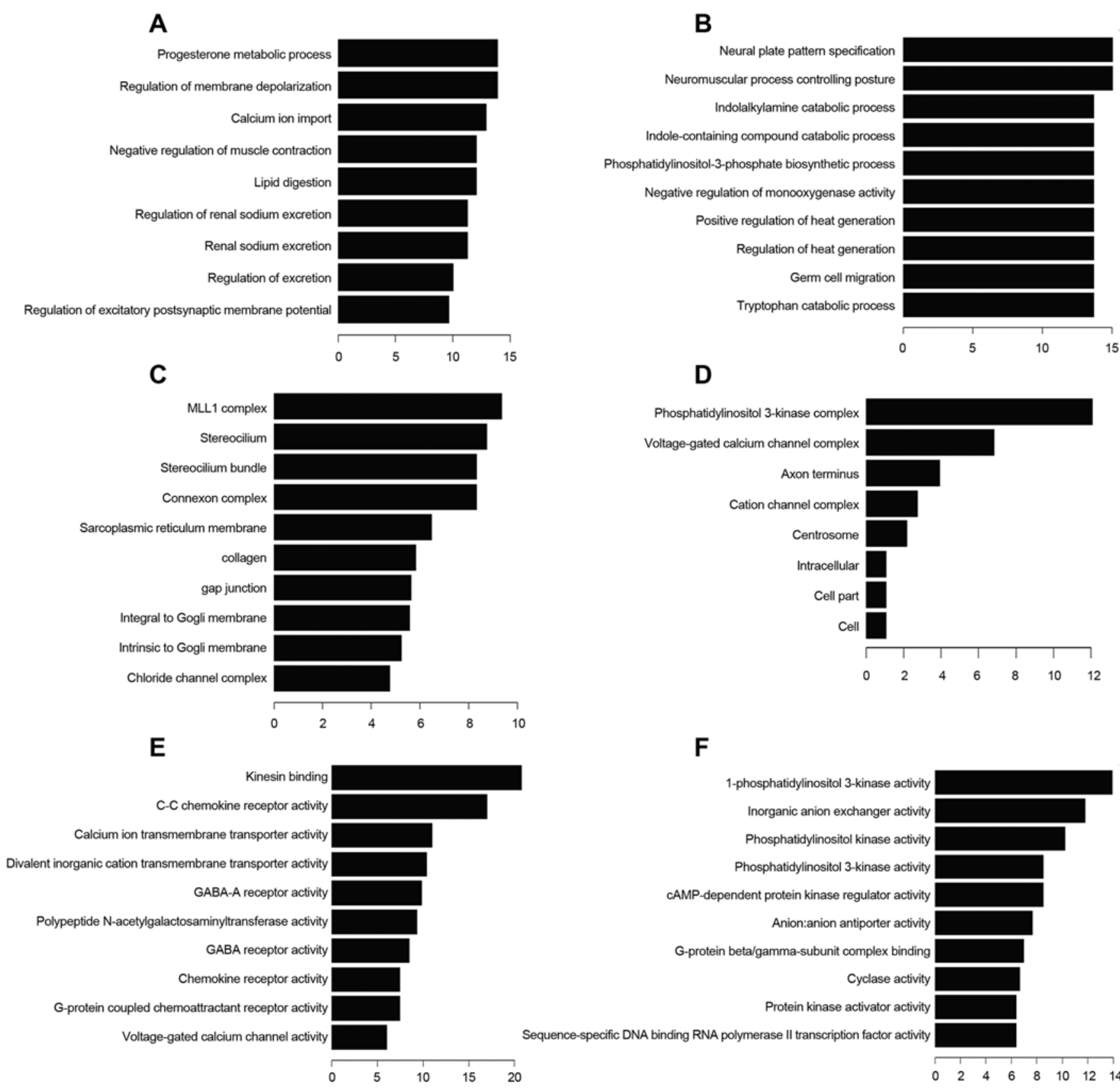

D
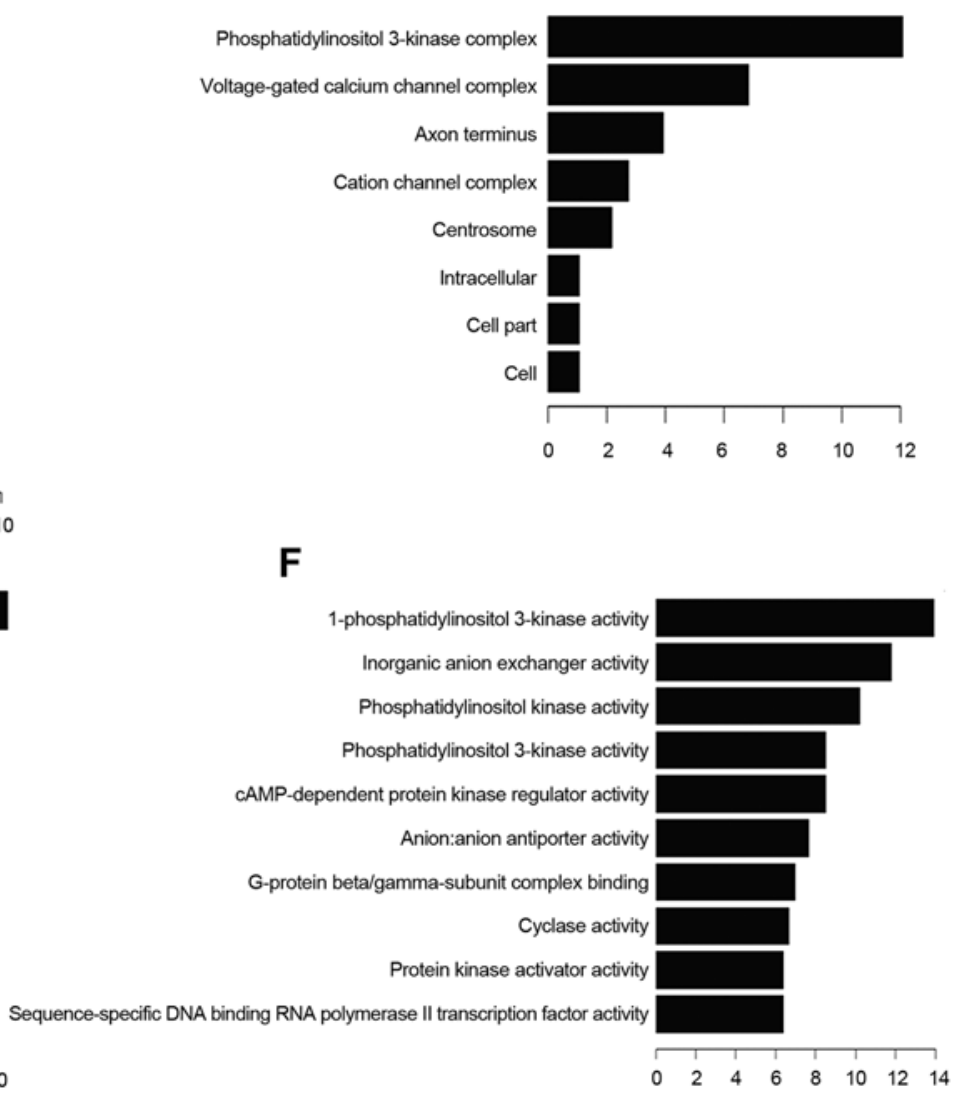

Figure 4. Gene ontology analysis results show the differently expressed coding gene transcripts associated with biological process (BP), cellular components (CC) and molecular function (MF). The most frequent fold enrichment biological processes (BP) associated with upregulated (A) and downregulated (B) coding gene transcripts. The most frequent fold enrichment cellular components (CC) associated with upregulated (C) and downregulated (D) coding gene transcripts. The most frequent fold enrichment molecular functions (MF) associated with upregulated (E) and downregulated (F) coding gene transcripts.

cytometry after HEC-1-B transfection with ASLNC04080 and negative control siRNA. Knockdown of ASLNC04080 expression increased apoptosis in HEC-1-B cells (NC vs. siRNA-1535: $15.9 \pm 0.66 \%$ vs. $26.9 \pm 1.27 \%$, T-test $\mathrm{P}<0.05)$ (Fig. 6C). Moreover, caspase- 3 protein cleavage was detected only in siRNA-1535 transfected cells (Fig. 6D). We performed cell cycle assays after siRNA transfection $48 \mathrm{~h}$. Knockdown of ASLNC04080 expression induced G1 phase arrest (NC vs. siRNA-1535: $41.14 \pm 1.10 \%$ vs. $49.85 \pm 0.77 \%$, t-test $\mathrm{P}<0.05$ ) (Fig. 6E).

These findings suggest that the ASLNC04080 IncRNA could regulate endometrial carcinoma cell HEC-1-B proliferation, apoptosis and cell cycle.

\section{Discussion}

Molecular alterations in endometrial carcinoma have been studied for many years $(14,15)$. Microsatellite instability (MI), and gene mutations (PTEN, K-RAS and PIK3CA) have been shown involved in type I endometrial carcinoma. Type II endometrial carcinoma exhibits mutations of p53, loss of heterozygosity (LOH), and molecular alterations (STK1 5, p16, and c-erb-B2). Recently a comprehensive, multiplatform analysis of 373 endometrial carcinomas identified new hotspot mutations in POLE, and based on the genomic characterization they classified endometrial cancers into four categories: POLE ultramutated, microsatellite instability hypermutated, copy- 


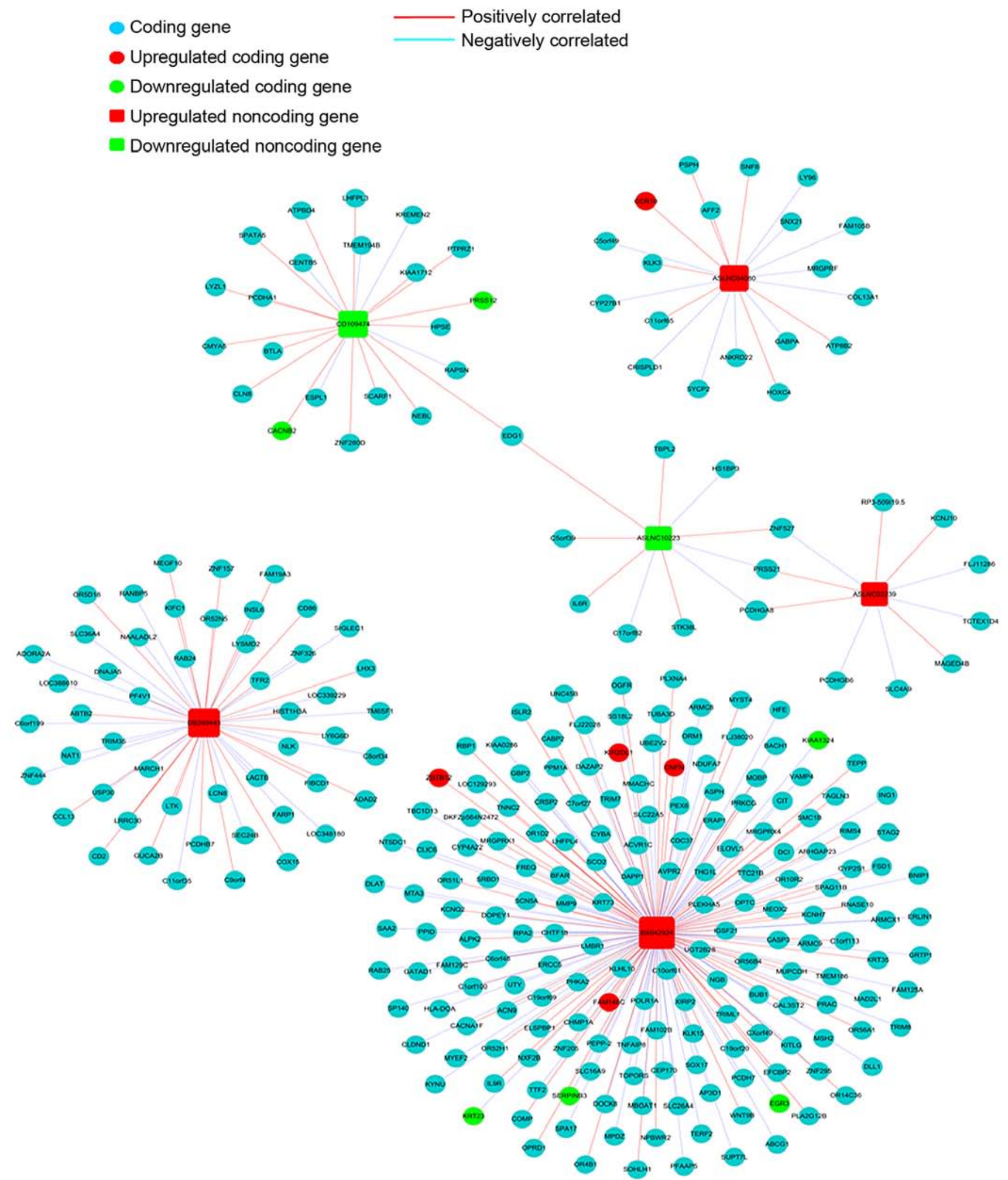

Figure 5. The co-expression network construction. Six selected lncRNAs were co-expression with 298 coding gene transcripts. ASLNC04080 expression correlates with 19 coding gene transcripts $(\mathrm{PCC}>0.95$ ).

number low, and copy-number high (16). The efforts on the integrated analysis of molecules not only help us to construct new tumor classifications, but also affect treatment recommendations for patients, provides opportunities for genome-guided clinical trials and drug development. Besides the known coding genes, noncoding RNAs act as a new hallmark for endometrial carcinoma diagnosis and therapy, have attracted wide attention. A large quantity of miRNAs target important genes in tumor development and progression has been identified in endometrial carcinoma (17). Hiroki et al (18), identified 

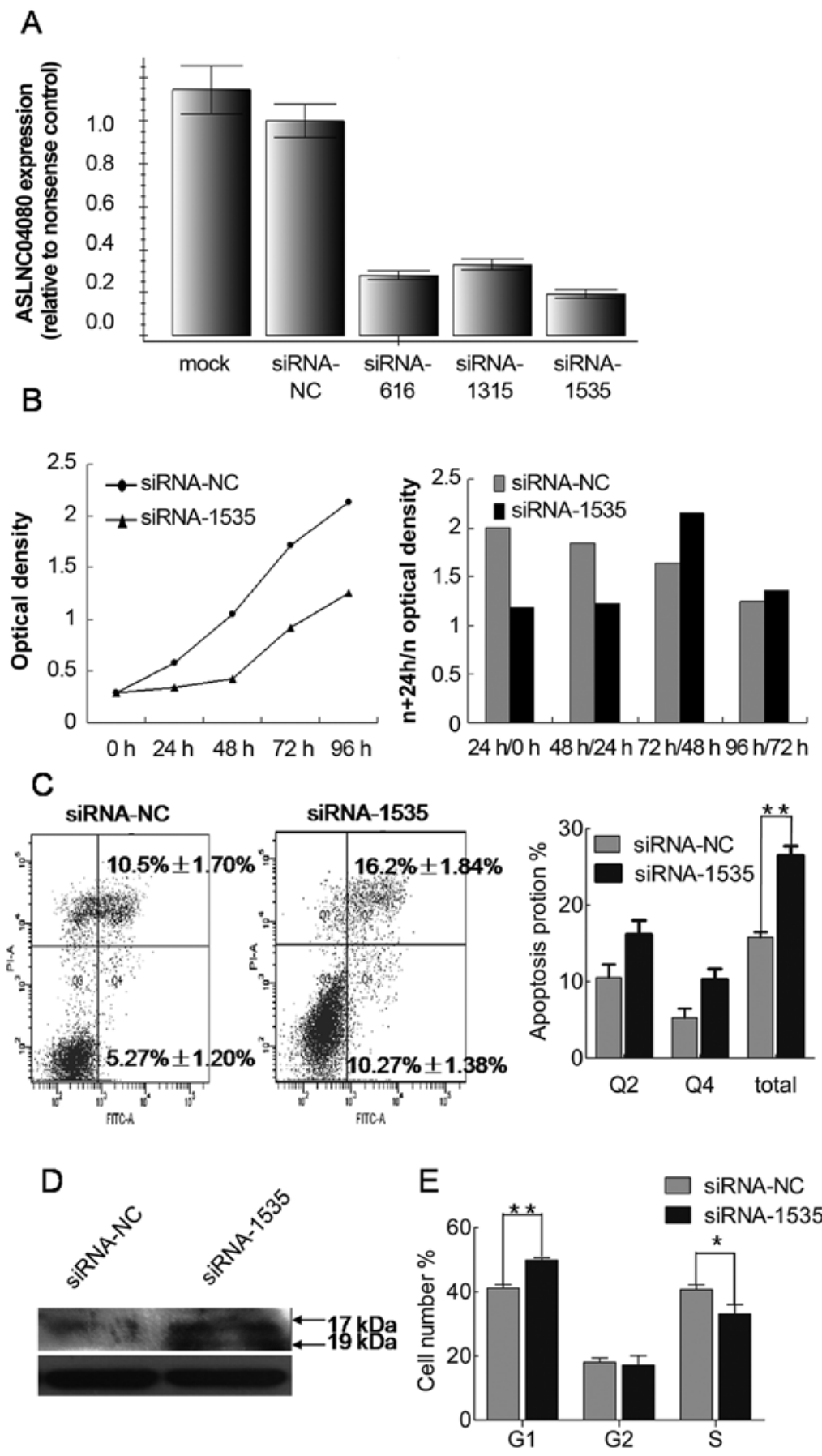

Figure 6. Inhibition of the ASLNC04080 expression suppressed proliferation, increased apoptosis and induced G1 phase arrest in HEC-1-B cells. (A) Knockdown efficiency of ASLNC04080 specific siRNAs in HEC-1-B cells. All 3 siRNA molecules induced $>50 \%$ inhibition of ASLNC04080 expression, and siRNA-1535 caused $>80 \%$ reduction in efficiency of ASLNC04080 expression. (B) CCK8 cell proliferation assays in HEC-1-B cells. The siRNA-1535 transfection induced lower growth rate. Especially in the first $48 \mathrm{~h}$ the cell growth rate was inhibited in ASLNC04080 expression knockdown cells. (C) Transfection of siRNA-1535 significantly induced HEC-1-B cell apoptosis (NC vs. siRNA-1535: $15.9 \pm 0.66 \%$ vs. $26.9 \pm 1.27 \%$, t-test p<0.001). (D) Western blotting revealed cleaved caspase-3 only in ASLNC04080 expression knockdown cells. (E) Knockdown of ASLNC04080 expression induced G1 phase arrest in HEC-1-B cells (NC vs. siRNA-1535: $41.14 \pm 1.10 \%$ vs. $49.85 \pm 0.77 \%$, t-test $\mathrm{p}<0.001$ ).

120 miRNAs deregulated in endometrial serous carcinoma. Moreover, their results showed that microRNA expression is associated with clinical pathology and prognosis of patients with endometrial serous adenocarcinoma.

LncRNA has been confirmed to regulate gene expression in histone modification (19), regulation of transcription (20) and splicing, and plays an essential role in cellular proliferation, development and metabolism (21). The deregulation of IncRNA is associated with physiological disorders and disease development (22). Increased lncRNAs correlated with carcinogenesis and tumor progression have been discovered accompanied with sequencing and microarray technological development. A series of differentially expressed lncRNAs (IncRNA-HEIH, IncRNA-MVIH, IncRNA-LALR1, IncRNA-LET and IncRNADreh) have been identified between HBV-related HCC and paired peritumoral tissues by microarray (23-25). With 
Table III. Upregulated coding gene transcripts corresponding to 12 pathways.

\begin{tabular}{|c|c|c|c|}
\hline Pathway ID & Definition & Fisher - P-value & Genes \\
\hline hsa05032 & $\begin{array}{l}\text { Morphine addiction - Homo sapiens } \\
\text { (human) }\end{array}$ & 0.004254111 & $\begin{array}{l}\text { ADORA1//GABRB1//GABRQ// } \\
\text { PDE3A//PRKCG }\end{array}$ \\
\hline hsa00512 & $\begin{array}{l}\text { Mucin type O-Glycan biosynthesis - } \\
\text { Homo sapiens (human) }\end{array}$ & 0.00528077 & GALNT13//GALNTL6//ST3GAL2 \\
\hline hsa04972 & $\begin{array}{l}\text { Pancreatic secretion - Homo sapiens } \\
\text { (human) }\end{array}$ & 0.005316287 & $\begin{array}{l}\text { ATP2A1//ATP2B3//PLA2G1B// } \\
\text { PRKCG//PRSS2 }\end{array}$ \\
\hline hsa04974 & $\begin{array}{l}\text { Protein digestion and absorption - } \\
\text { Homo sapiens (human) }\end{array}$ & 0.01848372 & COL12A1//COL1A2//COL4A6//PRSS2 \\
\hline hsa04672 & $\begin{array}{l}\text { Intestinal immune network for IgA } \\
\text { production - Homo sapiens (human) }\end{array}$ & 0.01969566 & CCR10//CCR9//CD86 \\
\hline hsa00140 & $\begin{array}{l}\text { Steroid hormone biosynthesis - } \\
\text { Homo sapiens (human) }\end{array}$ & 0.02776873 & AKR1C1//CYP19A1//UGT2B28 \\
\hline hsa04510 & $\begin{array}{l}\text { Focal adhesion - Homo sapiens } \\
\text { (human) }\end{array}$ & 0.03121468 & $\begin{array}{l}\text { COL1A2//COL4A6//MYLPF// } \\
\text { PAK4//PRKCG//VEGFC }\end{array}$ \\
\hline hsa00592 & $\begin{array}{l}\alpha \text {-Linolenic acid metabolism - } \\
\text { Homo sapiens (human) }\end{array}$ & 0.03328378 & ACOX3//PLA2G1B \\
\hline hsa04950 & $\begin{array}{l}\text { Maturity onset diabetes of the young - } \\
\text { Homo sapiens (human) }\end{array}$ & 0.03328378 & HNF4A//NKX2-2 \\
\hline hsa05211 & $\begin{array}{l}\text { Renal cell carcinoma - Homo sapiens } \\
\text { (human) }\end{array}$ & 0.04036226 & GAB1//PAK4//TCEB2 \\
\hline hsa00514 & $\begin{array}{l}\text { Other types of O-glycan biosynthesis - } \\
\text { Homo sapiens (human) }\end{array}$ & 0.04651509 & GLT25D2//RFNG \\
\hline hsa04014 & $\begin{array}{l}\text { Ras signaling pathway - Homo sapiens } \\
\text { (human) }\end{array}$ & 0.0466148 & $\begin{array}{l}\text { ANGPT4//GAB1//PAK4//PLA2G1B// } \\
\text { PRKCG//VEGFC }\end{array}$ \\
\hline
\end{tabular}

further studies, these lncRNAs were verified to be functional molecules contributing to HCC tumor growth, angiogenesis, metastasis and serving as a predictor for HCC patients' poor recurrence-free survival after hepatectomy. Although a systematic study of lncRNA in endometrial carcinoma is lacking, a few functional lncRNAs have been shown deregulated in endometrial carcinoma. LncRNA NCT25 mutations were observed in endometrial tumor specimens (in 23 of 48 of the samples), and could be a mutational target specifically in endometrial cancer. MALAT1 upregulation is the result of tumor suppressor PCDH10 silencing in endometrioid cancer (13). Therefore, more functional lncRNA could be related to endometrial carcinoma genesis and progression, and act as potential hallmark for endometrial carcinoma diagnosis and therapy.

To investigate the lncRNA expression profile of endometrial carcinoma, we performed a microarray analysis containing lncRNA and coding gene information in 3 paired endometrial carcinoma and adjacent non-tumor tissues. The microarray data showed a significant difference of lncRNA expression pattern between endometrial carcinoma and adjacent non-tumor tissues. A total of $53 \operatorname{lncRNAs}$ (C vs. N: 39 up-, 14 down-regulation, fold change $>2.0, \mathrm{p}<0.05$ ) were deregulated in endometrial carcinoma. ASLNC04080 is the most upregulated lncRNA in endometrial carcinoma (fold change: $3.379, \mathrm{p}=0.03778$ ). The expression level of ASLNC04080 is higher in endometrial carcinoma tissues (22/24) compared with non-tumor tissues. ASLNC04080 expression could also be detected in endometrial carcinoma cell line HEC-1-B as well as other gynecological cancer cell lines (Siha, HeLa, $3 \mathrm{AO}$ and SKOV3). ASLNC04080 is transcribed from the chr1: -28905061 - -28909492 loci (1 p35.3), consisting 6 exons 1,867 nt in length.

According to the coding gene microarray data 46 mRNAs (C vs. N: 26 up-, 20 down-regulation, fold change $>2.0, \mathrm{p}<0.05$ ) exhibited a different expression between paired endometrial carcinoma and adjacent non-tumor tissues. Previous studies demonstrated that PTEN mutations occur early in endometrial carcinogenesis and co-exist frequently with other deregulated molecules targeting AKT-PI3K-mTOR pathway. Through pathway analysis, we have found 6 up- and 9 down-regulated coding gene transcripts in endometrial carcinoma targeting Ras signaling pathway. Estrogen and progesterone accession and metabolism are related to endometrial carcinoma genesis and progression (26). In our data progesterone metabolic process is one of the most frequent fold enrichment biological processes. Two endometrial carcinoma upregulated coding gene transcripts CYP19A1 and AKR1C1 participated in this processes, and correlated with endometrial carcinoma genesis $(27,28)$. Besides, 31 deregulated coding transcripts target the wound healing process. Growth evidence shows that voltage-gated channel activity alteration of carcinoma cell membrane is a characteristic of carcinoma cells (29-31). In our results, the molecules target voltage-gated ion channel activity, voltage-gated channel activity, voltage-gated cation 
Table IV. Downregulated coding gene transcripts corresponding to 12 pathways.

\begin{tabular}{|c|c|c|c|}
\hline Pathway ID & Definition & Fisher - P-value & Genes \\
\hline hsa04015 & $\begin{array}{l}\text { Rap1 signaling pathway - Homo sapiens } \\
\text { (human) }\end{array}$ & 0.002010251 & $\begin{array}{l}\mathrm{CSF} 1 / / \mathrm{FGF} 13 / / \mathrm{GNAQ} / / \mathrm{HGF} / / \mathrm{ITGAM} / / \\
\text { ITGB1//KITLG//MLLT4//PIK3CB }\end{array}$ \\
\hline hsa05152 & Tuberculosis - Homo sapiens (human) & 0.00262324 & $\begin{array}{l}\text { ARHGEF12//ATP6V0A2//CYP27B1// } \\
\text { HLA-DOA//IL10//ITGAM//NFYC//PIK3C3 }\end{array}$ \\
\hline hsa04014 & $\begin{array}{l}\text { Ras signaling pathway - Homo sapiens } \\
\text { (human) }\end{array}$ & 0.003095239 & $\begin{array}{l}\text { CSF1//ETS1//FGF13//HGF//KITLG// } \\
\text { MLLT4//PIK3CB//PLA2G4A//SHC1 }\end{array}$ \\
\hline hsa05146 & Amoebiasis - Homo sapiens (human) & 0.003198103 & $\begin{array}{l}\text { COL5A2//GNAQ//IL10//ITGAM// } \\
\text { PIK3CB//SERPINB3 }\end{array}$ \\
\hline hsa00380 & $\begin{array}{l}\text { Tryptophan metabolism - Homo sapiens } \\
\text { (human) }\end{array}$ & 0.0158507 & ACMSD//KYNU//OGDHL \\
\hline hsa05140 & Leishmaniasis - Homo sapiens (human) & 0.01747982 & HLA-DOA//IL10//ITGAM//ITGB1 \\
\hline hsa04270 & $\begin{array}{l}\text { Vascular smooth muscle contraction - } \\
\text { Homo sapiens (human) }\end{array}$ & 0.03014367 & $\begin{array}{l}\text { ARHGEF12//GNAQ//GUCY1A3// } \\
\text { KCNU1//PLA2G4A }\end{array}$ \\
\hline hsa04970 & Salivary secretion - Homo sapiens (human) & 0.03164653 & ATP1A2//GNAQ//GUCY1A3//STATH \\
\hline hsa04912 & $\begin{array}{l}\text { GnRH signaling pathway - Homo sapiens } \\
\text { (human) }\end{array}$ & 0.03392592 & GNAQ//GNRH1//MAP3K3//PLA2G4A \\
\hline hsa04964 & $\begin{array}{l}\text { Proximal tubule bicarbonate reclamation - } \\
\text { Homo sapiens (human) }\end{array}$ & 0.03706998 & ATP1A2//SLC4A4 \\
\hline hsa05150 & $\begin{array}{l}\text { Staphylococcus aureus infection - } \\
\text { Homo sapiens (human) }\end{array}$ & 0.04175273 & HLA-DOA//IL10//ITGAM \\
\hline hsa04730 & $\begin{array}{l}\text { Long-term depression - Homo sapiens } \\
\text { (human) }\end{array}$ & 0.04544242 & GNAQ//GUCY1A3//PLA2G4A \\
\hline
\end{tabular}

channel activity and voltage-gated calcium channel activity, displaying deregulation in endometrial carcinoma.

We constructed a coding-non-coding gene co-expression network (CNC), by analyzing the correlation of lncRNAs and the expression level of the coding gene transcripts. The expression of six selected lncRNAs were showed to be related to 289 coding gene transcripts. The BX642924 expression was correlated with 177 coding gene transcripts (Fig. 5), especially positively correlated to PRKCG (upregulated in endometrial cacionoma, PCC >0.98) and negatively correlated to KITLG (downregulated in endometrial cacionoma, PCC >0.0.95) expression. Both PRKCG and KITLG were involved in Ras signaling pathway, and have been showed related to tumor genesis and progression $(32,33)$. According to these analyses we speculate that BX642924 may correlate with the Ras signaling pathway. The expression of three coding gene transcripts (ZNF275, PCDHGA8, PRSS21) was correlated with ASLNC02239 (upregulated in endometrial carcinoma) and ASLNC10223 (downregulated in endometrial carcinoma), showing a possible relation among these genes. More work is needed to confirm the relations and the underlying regulation mechanism of these coding and noncoding genes.

ASLNC04080 expression is correlated with 19 coding gene transcripts. KLK3 is the most positively related transcript with ASLNC04080 (PCC >0.97). Increasing evidence indicates that KLK3 (kallikrein-related peptidase 3) is implicated in carcinogenesis and acts as a biomarker or a diagnosis target in multiple types of cancer (34). Moreover, SYCP2 negatively correlates with ASLNC04080 expression (PCC >0.95), and have been shown to participate in the cell cycle pathway (35). Inhibition of ASLNC04080 expression in HEC-1-B cells, resulted in decreased cell proliferation, increased cell apoptosis and G1 phase arrest. Taking together, these findings suggest that ASLNC04080 is a functional lncRNA in human endometrial carcinoma and may contribute to carcinogenesis via interaction with other coding genes. More exploration of the function mechanism of ASLNC04080 is required.

To our knowledge, this is the first systematic research project of lncRNA expression profile in endometrial carcinoma. We found several lncRNAs expressed in endometrial carcinoma and correlated with multiple Gene Ontology and pathways involved in carcinogenesis. These findings could help us enrich the knowledge on the mechanism of endometrial carcinogenesis and find new diagnostic or therapeutic targets for endometrial carcinoma.

\section{References}

1. Siegel R, Ma JM, Zou ZH and Jemal A: Cancer Statistics, 2014. CA Cancer J Clin 64: 9-29, 2014.

2. Bokhman JV: Two pathogenetic types of endometrial carcinoma. Gynecol Oncol 15: 10-17, 1983.

3. Liu FS: Molecular carcinogenesis of endometrial cancer. Taiwan J Obstet Gynecol 46: 26-32, 2007.

4. Matias-Guiu X and Prat J: Molecular pathology of endometrial carcinoma. Histopathology 62: 111-123, 2013.

5. Mercer TR, Dinger ME and Mattick JS: Long non-coding RNAs: insights into functions. Nat Rev Genet 10: 155-159, 2009.

6. Ponting CP, Oliver PL and Reik W: Evolution and functions of long noncoding RNAs. Cell 136: 629-641, 2009. 
7. Wang F, Li X, Xie X, Zhao L and Chen W: UCA1, a non-proteincoding RNA up-regulated in bladder carcinoma and embryo, influencing cell growth and promoting invasion. FEBS Lett 582: 1919-1927, 2008

8. Yang C, Li X, Wang Y, Zhao L and Chen W: Long non-coding RNA UCA1 regulated cell cycle distribution via CREB through PI3-K dependent pathway in bladder carcinoma cells. Gene 496 8-16, 2012

9. Wang Y, Chen W, Yang C, et al: Long non-coding RNA UCA1a (CUDR) promotes proliferation and tumorigenesis of bladder cancer. Int J Oncol 41: 276-284, 2012.

10. Li Z, Li X, Wu S, Xue M and Chen W: Long non-coding RNA UCA1 promotes glycolysis by upregulating hexokinase 2 through the mTOR-STAT3/microRNA143 pathway. Cancer Sci 105: 951-955, 2014.

11. Wu W, Bhagat TD, Yang X, et al: Hypomethylation of noncoding DNA regions and overexpression of the long noncoding RNA, AFAP1-AS1, in Barrett's esophagus and esophageal adenocarcinoma. Gastroenterology 144: 956-966.e4, 2013.

12. Weber DG, Johnen G, Casjens S, et al: Evaluation of long noncoding RNA MALAT1 as a candidate blood-based biomarker for the diagnosis of non-small cell lung cancer. BMC Res Notes 6: 518, 2013.

13. Zhao Y, Yang Y, Trovik J, et al: A novel wnt regulatory axis in endometrioid endometrial cancer. Cancer Res 74: 5103-5117, 2014.

14. Bansal N, Yendluri V and Wenham RM: The molecular biology of endometrial cancers and the implications for pathogenesis, classification, and targeted therapies. Cancer Control 16: 8-13, 2009.

15. Yeramian A, Moreno-Bueno G, Dolcet X, et al: Endometrial carcinoma: molecular alterations involved in tumor development and progression. Oncogene 32: 403-413, 2013.

16. Getz G, Gabriel SB, Cibulskis K, et al: Integrated genomic characterization of endometrial carcinoma. Nature 497: 67-73, 2013.

17. Devor EJ, Hovey AM, Goodheart MJ, Ramachandran S and Leslie KK: microRNA expression profiling of endometrial endometrioid adenocarcinomas and serous adenocarcinomas reveals profiles containing shared, unique and differentiating groups of microRNAs. Oncol Rep 26: 995-1002, 2011.

18. Hiroki E, Akahira J, Suzuki F, et al: Changes in microRNA expression levels correlate with clinicopathological features and prognoses in endometrial serous adenocarcinomas. Cancer Sci 101: 241-249, 2010.

19. Joh RI, Palmieri CM, Hill IT and Motamedi M: Regulation of histone methylation by noncoding RNAs. Biochim Biophys Acta 1839: 1385-1394, 2014.

20. Bonasio R and Shiekhattar R: Regulation of transcription by long noncoding RNAs. Annu Rev Genet 48: 433-455, 2014.

21. Kornfeld JW and Brüning JC: Regulation of metabolism by long, non-coding RNAs. Front Genet 5: 57, 2014.
22. Schonrock N, Harvey RP and Mattick JS: Long noncoding RNAs in cardiac development and pathophysiology. Circ Res 111: $1349-1362,2012$

23. Yang F, Zhang L, Huo XS, et al: Long noncoding RNA high expression in hepatocellular carcinoma facilitates tumor growth through enhancer of zeste homolog 2 in humans. Hepatology 54: 1679-1689, 2011.

24. Xu D, Yang F, Yuan JH, et al: Long noncoding RNAs associated with liver regeneration 1 accelerates hepatocyte proliferation during liver regeneration by activating $W n t / \beta$-catenin signaling. Hepatology 58: 739-751, 2013.

25. Yang F, Huo XS, Yuan SX, et al: Repression of the long noncoding RNA-LET by histone deacetylase 3 contributes to hypoxia-mediated metastasis. Mol Cell 49: 1083-1096, 2013.

26. Ito K, Utsunomiya $\mathrm{H}$, Yaegashi $\mathrm{N}$ and Sasano $\mathrm{H}$ : Biological roles of estrogen and progesterone in human endometrial carcinoma new developments in potential endocrine therapy for endometrial cancer. Endocr J 54: 667-679, 2007.

27. Berstein LM, Imyanitov EN, Suspitsin EN, et al: CYP19 gene polymorphism in endometrial cancer patients. J Cancer Res Clin Oncol 127: 135-138, 2001.

28. Rizner TL, Smuc T, Rupreht R, Sinkovec J and Penning TM: AKR1C1 and AKR1C3 may determine progesterone and estrogen ratios in endometrial cancer. Mol Cell Endocrinol 248 126-135, 2006

29. Roger S, Potier M, Vandier C, Besson P and Le Guennec JY: Voltage-gated sodium channels: new targets in cancer therapy? Curr Pharm Des 12: 3681-3695, 2006.

30. Fraser SP, Ozerlat-Gunduz I, Brackenbury WJ, et al: Regulation of voltage-gated sodium channel expression in cancer: hormones, growth factors and auto-regulation. Philos Trans R Soc Lond B Biol Sci 369: 20130105, 2014.

31. Brackenbury WJ: Voltage-gated sodium channels and metastatic disease. Channels 6: 352-361, 2012.

32. Zhang Y, Hu X, Wang HK, et al: Single-nucleotide polymorphisms of the PRKCG gene and osteosarcoma susceptibility. Tumour Biol 35: 12671-12677, 2014.

33. Kanetsky PA, Mitra N, Vardhanabhuti S, et al: Common variation in KITLG and at $5 \mathrm{q} 31.3$ predisposes to testicular germ cell cancer. Nat Genet 41: 811-815, 2009.

34. Cicek MS, Liu X, Casey G and Witte JS: Role of androgen metabolism genes CYP1B1, PSA/KLK3, and CYP11alpha in prostate cancer risk and aggressiveness. Cancer Epidemiol Biomarkers Prev 14: 2173-2177, 2005.

35. Kouznetsova A, Novak I, Jessberger R and Hoog C: SYCP2 and SYCP3 are required for cohesin core integrity at diplotene but not for centromere cohesion at the first meiotic division. J Cell Sci 118: 2271-2278, 2005. 